\title{
CERRADO, ENTRE CASCAS E RAÍZES: UMA EXPERIÊNCIA \\ Desmontando o Grupo Faz de Conta
}

\section{CERRADO, BETWEEN BARK AND ROOTS: AN EXPERIENCE}

\author{
Disassembling Grupo Faz de Conta
}

Angie Mendonça ${ }^{1}$

\section{Resumo}

Este artigo reflete sobre o processo da desmontagem, embasada nos direcionamentos de Ileana Diéguez, do espetáculo Cerrado, entre cascas e raízes, mais recente montagem do Grupo Faz de Conta, apresentado na cidade de Uberlândia, contextualizando com um breve histórico do grupo citado. É o intuito desta escrita apresentar os caminhos que levaram o grupo a conceber a investigação sobre as possíveis relações estabelecidas pelo boneco entre as fases de construção do mesmo e a montagem de cena; ou as possibilidades que a cena propõe para a construção de um boneco, em uma alteração das etapas comuns de criação e produção em um espetáculo de formas animadas. Será desvelado o processo de montagem do espetáculo, focando nos bonecos que entram em cena, na intenção de contribuir para a pesquisa e reflexão no âmbito do teatro de animação.

Palavras-chave: Grupo Faz de Conta. Cerrado, entre cascas e raízes. Teatro de Animação. Bonecos.

\section{Resumen}

Este artículo reflexiona un proceso de desmontaje, con base en las instrucciones de Ileana Dieguez, del espectáculo Cerrado, entre cáscaras y raíces, el último montaje del Grupo Faz de Conta, presentado en Uberlândia, contextualizando con un breve historico del grupo citado. Es el propósito de este trabajo la comprensión de los caminos que llevaron el grupo para desarrollar la investigación sobre los posibles enlaces establecidos por el títere entre las fases de construcción del mismo y montaje de una escena, o las posibilidades que la escena sugiere para la construcción de un títere, en una alteración de las fases de creación y producción de un espectáculo de formas animadas. Será develado el proceso de montaje del espectáculo, centrándose en los títeres que entran en escena, con la intención de contribuir a la investigación y la reflexión en el teatro de animación.

Palabras clave: Grupo Faz de Conta. Cerrado, entre cáscaras y raíces. Teatro de Animación. Títeres.

Abstract

This article reflects on the process of disassembling based on the directions of Ileana Dieguez, the play Cerrado, between barks and root, latest assembly of Grupo Faz de Conta, presented at the city of Uberlândia, contextualizing with a brief history of the cited group. It is the intent of this writing to present the paths that led the group to develop research on the possible relations established by the puppet's phases among the

\footnotetext{
${ }^{1}$ Mestranda em Artes Cênicas pela Universidade Federal de Uberlândia, ex-integrante do grupo Giramundo, pesquisadora e bonequeira do Grupo Faz de Conta. E-mail: mendonça.angie@gmail.com
} 
construction of the this and assembly of the scene; or the possibility that the scene proposes to build a puppet, in a change of the common steps in creating and producing a spectacle of animated forms. The assembly process of the show will be unveiled, focusing on puppet that comes into the scene, with the intention of contributing to research and reflection under the animated theater.

Keywords: Grupo Faz de Conta. Cerrado, between bark and roots. Animation Theatre. Puppet.

Aventuro-me nestas próximas palavras a desmontar o espetáculo Cerrado, entre cascas e raízes, montagem do Grupo Faz de Conta do ano de 2012, com foco no processo de construção dos bonecos elencados na peça. Enfatizo o diálogo que estes bonecos criaram entre a oficina - etapa da construção e a sala de ensaio - etapa da montagem das cenas, e a alteração dessas etapas como possibilidade de metodologia de pesquisa no teatro de animação.

Para esclarecer essa estratégia de desvelamento do processo de criação, sigo à luz de Ileana Dieguez, que traduz a desmontagem da seguinte forma,

\begin{abstract}
Desmontar esos recorridos implicó develar algunas relaciones entre investigación y creación, pues no son principios repetidos o conocidos los que se entregan, sino los laberintos que se experimentam aun a costa del llamado éxito. Optar por compartir processos de trabajo, y no sólo mostrar resultados, es emprender itinerarios arriesgados, en uma dirección muy distinta al montaje o representación de um texto prévio. Lo que se decide compartir o mostrar no es una técnica o regla de cómo hacer el trabajo de mesa para interpretar el texto o cómo repartir los papeles entre los actores y marcales um trazo escénico. Quizás por ello estas experiencias contribuyen a extender el horizonte de estrategias poéticas, ponen a prueba los tradicionales cânones, abren puertas, oxigenan los marcos y, muy especialmente, proponen nuevos retos para quienes estudian y reflexionan em torno a la escena. (DIÉGUEZ, 2009, p. 10 , grifos da autora)
\end{abstract}

A bordo deste conceito, narro a trajetória do Grupo Faz de Conta até o momento da sua última montagem e o percurso que o levou até a pesquisa citada. Desnudo os processos internos do grupo em construir bonecos na ânsia de compartilhar experiências adquiridas e propor novas reflexões entorno do processo de montagem no teatro de animação.

O espetáculo Cerrado, entre cascas e raízes é um marco para o grupo em diversas instâncias, foi um grande salto qualitativo para o Faz de Conta e condensou várias pesquisas que o grupo vinha fazendo em seus vinte anos de carreira. Apresentar seus mecanismos internos, suas falhas e êxitos, é com certeza um grande desafio.

Velha Cerradina - Desde menina que eu ando descalça, desde menina que eu gosto de pisar no chão deste cerrado... 
Menina Cerradina - Eu gosto de afundar meu pé na terra, na lama.

Velha Cerradina - Era eu quem pegava lenha para acender o fogo à noite.

Menina Cerradina - Eu subo nas arvóres, nas montanhas, monto cavalo em pelo, mamo manga do pé, chupo murici azedo...

Velha Cerradina - E tomo banho de cachoeira!!!! E pego vagalume...Vagalume, Tum Tum, seu pai t’aqui, sua mãe também!

Menina Cerradina - Vagalume Tum Tum, seu pai t'aqui, sua mãe morreu!

Ah, a noite fresca, cheia dos cheiros de capim gordura e mumbeca. Os curiangos voejam daqui pra li.

A lua quando cheia ilumeia todo o campo até as chegança do grotão, faz sombra nas árvores que derramam os galhos tortos no chão, entrelaçados que nem casalzinho. $\mathrm{O}$ céu salpicado de estrela parece de pegar com a mão. E, quando é de dia é de um azulão espalhado acabando com um beijo na terra. Eu gosto de deitar na grama, de ver a flora amarela do ipê, a quaresmeira roxa num bonito combinado, eu gosto de ver o bailar das folhas caindo das árvores, o desenho das nuvens, o vôo dos pássaros. Tem quero-quero, tem curió, tem assanhaçu, bem-te-vi, curicaca, tem tucano, tem arara, tem carcará, e tinha sabiá.

Sabiá fugiu do terreiro, foi cantar no abacateiro, e a menina triste a chamar vem cá sabiá... (GRUPO FAZ DE CONTA, 2012)

Assim, eu entrava no palco - semicírculo, delimitado na praça por um grande tapete de retalhos; como pano de fundo um tecido branco esticado na vertical de 4 metros de altura por 6 metros de largura, onde eram feitas as projeções de vídeo e de sombra.

A Velha Cerradina vivendo o presente, relembrando um cerrado extinto; a Menina Cerradina - seu passado, sua lembrança invocada em um tempo presente. Eu, a Menina, dividindo o palco com a Velha, minha mãe, Maria Inês Mendonça.

Mas para desmontar esse espetáculo, eu preciso voltar um pouco no tempo. É necessário desvelar toda a história que me atravessa, que perpassa pelo grupo, caminha entre minha família e se ilumina neste encontro de Cerradinas. Começo contando outra história.

No dia 22 de Julho de 1988, Maria Inês Mendonça, dona de casa, mãe de três filhas, mudava a trajetória da sua vida. Em um concurso promovido pela Prefeitura da sua cidade, Maria Inês subia ao palco pela primeira vez como Vovó Caximbó: velhinha contadora de histórias que a acompanharia por toda a sua vida. Depois desse dia, nunca mais desceu. Passados cinco anos, fez um curso de Fantolixo - técnica de construção de boneco tipo muppet que utiliza materiais reutilizados - e começou, no quintal da própria 
casa, a fazer bonecos com as amigas no intuito de vender. Nunca conseguiu desapegar das criações. Então resolveu usar os bonecos em um espetáculo; Histórias Folclóricas foi a primeira peça do Grupo Faz de Conta, fundado naquele ano de 1993.

O Grupo Faz de Conta desde seu surgimento era fundado sobre pilares que sustentariam toda a sua trajetória: a participação familiar, a cultura popular e a reutilização de materiais.

Apesar de o grupo ter se iniciado entre amigas, tão logo foi se desenvolvendo abarcou a primeira filha, Pollyana Mendonça, que após alguns anos acompanhando nossa mãe pelos palcos, decidiu enfim, que sua contribuição para o grupo seria longe dos bonecos, na assessoria antropológica e na produção.

Logo passou pelo grupo a segunda filha, Tayná Mendonça, que também teve como primeira experiência a arena e os títeres. Ao contrário da primogênita, Tayná continuou seu envolvimento com as artes, mas afastada do palco. Separada do grupo por alguns anos, retornou neste último trabalho como figurinista.

E, por último, minha mãe me introduziu no grupo. Eu tomei gosto por tudo e fiquei. Me esbaldei, verticalizei minhas raízes neste grupo e me aprofundei em estudos e pesquisas. Os outros integrantes que passaram e os que atuam hoje no grupo são sempre de alguma forma adotados pela família, preservando nossa tradição familiar.

O segundo pilar, a cultura popular, sempre habitou nossa casa. Inserida na família pela minha mãe, ditou nossas brincadeiras, nossos cantos, nossos trabalhos. Pollyana, hoje, é antropóloga e trabalha com povos e comunidades tradicionais e suas referências culturais. Todos os espetáculos do grupo resgataram cada um a seu modo, um pouco do folclore da nossa região.

O terceiro pilar foi erguido por uma necessidade prática, quase nunca tínhamos dinheiro suficiente para produzir nossos espetáculos e, no corte orçamentário o primeiro da fila, até por ser o mais caro, era o material para a construção dos bonecos. A solução: conseguir outros materiais que fossem baratos ou até mesmo de graça.

Sobre esse terceiro pilar o grupo também construiu sua identidade e proposta de pesquisa. Atualmente, apesar de abordarmos estéticas diferenciadas a cada montagem, privilegiamos os materiais descartados para a construção dos bonecos.

Apesar de ser uma pesquisa muito rica e promissora, ela não é o alvo deste presente trabalho. Mas sim, outra pesquisa desenvolvida nos últimos anos pelo grupo: o trânsito de um boneco em fase de criação entre a oficina e a sala de ensaio, ou as possíveis 
contribuições que a montagem de uma cena pode oferecer para a construção do boneco, seja em mecanismos, deslocamento de eixo gravitacional, traços fisionômicos e até mesmo na estética do boneco.

Para tanto, adianto alguns anos da história do Grupo Faz de Conta, que foram os anos iniciais de descoberta das possibilidades e potencialidades do teatro de animação, até o momento que essa pesquisa se iniciou de forma mais contundente.

Avançamos para o ano de 2008, com o espetáculo História Contada: Porta Aberta, Semente Plantada. Este foi elaborado a partir da tradição secular da contação de histórias apresentado pela personagem Vovó Caximbó e acompanhada ao vivo por músicos. A montagem foi precedida por uma pesquisa que realizamos na região, sobretudo com pessoas idosas, visando resgatar a tradição oral e buscando referências nas festas populares e em manifestações tradicionais. Das 156 histórias que ouvimos, selecionamos 05 para a peça. Para contar estas histórias, utilizamos de várias técnicas de animação.

Neste período, eu estava afastada do grupo. Tinha me mudado para Belo Horizonte para fazer a graduação e estava trabalhando com o grupo Giramundo, com o qual obtive um amplo aprendizado. Minhas contribuições para a montagem do História Contada foram feitas de modo esporádico, durante minhas visitas. E, efetivamente, em um segundo momento em 2010, melhorando alguns bonecos, quando fizemos uma remontagem do espetáculo.

A história inicial era feita com alguns objetos que acoplados à mão da atriz/manipuladora Maria Inês, sugeriam a cabeça de um boneco. Esta forma animada foi utilizada na primeira montagem, mas consideramos os objetos muito pequenos e pouco visíveis, então, trocamos por cabeças de bonecos de manipulação direta.

Esta foi a primeira intervenção que a cena propôs para o boneco. Neste momento o diálogo não aconteceu durante a construção do boneco e a montagem da cena; mas sim, depois de testá-lo pronto em cena é que houve a decisão de trocá-lo por outro.

Na mesma história utilizávamos do teatro de sombras como recurso. Também neste os pantins $^{2}$ foram refeitos, no início eram figuras inteiriças, e na remontagem estas silhuetas foram reelaboradas e ganharam diversas articulações.

Os bonecos da segunda e terceira história, não foram radicalmente modificados; ganharam pequenas melhorias no acabamento e para a ergonomia da manipulação. Era um boneco habitável e um gigante, respectivamente.

\footnotetext{
${ }^{2}$ Pantins são formas bidimensionais utilizadas no teatro de sombras.
} 
Nesse processo, ainda de forma inconsciente, iniciamos o diálogo entre a construção dos bonecos e sua manipulação na cena. Uma vez que nós somos os construtores e manipuladores dos bonecos, esse diálogo é mais direto e intenso em comparação a outros processos que têm equipes diferenciada para construção e manipulação.

Em 2009, fizemos a montagem do espetáculo O Casamento da Dona Baratinha, com bonecos de balcão. Esta peça é uma releitura da fábula homônima; contextualizamos a história para uma barata moderna, que ganha na loteria, e tem por pretendentes animais que representam os pecados capitais.

Como eu trabalhava no Giramundo, achamos proveitoso aproximar mais membros do Faz de Conta a este processo tão específico de trabalho como é o do grupo belo horizontino. Maria Inês, Pollyana e Rafael Naufel ${ }^{3}$ foram para Belo Horizonte e montamos em minha casa uma oficina provisória.

Para esta montagem, convidamos Paulo Emílio $\mathrm{Luz}^{4}$ para coordenar a construção dos bonecos. Paulo trouxe o método de trabalho utilizado no Giramundo: o projeto de um boneco. A figura bidimensional que salta do papel, seguindo seus traços, formas e cores, esculpindo um corpo tridimensional; um desenho que tem por ordem se materializar em volume. O projeto de um boneco consiste na orientação do idealizador para o construtor através de desenho, ele atinge dois campos, o primeiro é o desenho artístico, onde cabe a estética do boneco, o conceito e a fisionomia; e depois o desenho técnico, que é feito por cima do primeiro, e encampa todas as dimensões, as articulações, eixos e até materiais.

Foram realizados projetos para todos os bonecos do Casamento, e seguimos à risca os desenhos, com pequenas alterações na fase de modelagem das cabeças feitas pelo próprio Paulo Emílio, autor de todos os projetos.

Estes bonecos foram para cena na etapa de acabamento, portanto sua estrutura nunca foi modificada, permanecendo inalterados desde sua concepção.

Essa montagem foi de extrema importância para o Grupo Faz de Conta, que pela primeira vez teve contato com o projeto detalhado do boneco. Atualmente, utilizamos esta técnica com algumas modificações, que foram sendo feitas no decorrer da experiência do grupo.

\footnotetext{
${ }^{3}$ Rafael Naufel é integrante do Grupo Faz de Conta, e pertencente à família desde 2003.

${ }^{4}$ Paulo Emílio Luz foi integrante do grupo Giramundo de 2001 a 2009. Hoje é integrante do grupo Terno de Teatro, do qual é também fundador.
} 
O próximo espetáculo, Um Natal para Pedrinho, 2010 - Auto de Natal que conta a saga de um garoto pobre às vésperas do Natal - foi iniciado com os projetos dos bonecos de manipulação direta, desta vez o desenho artístico foi assinado por Rafael Mazer ${ }^{5}$ e o técnico foi feito por todos os integrantes do grupo.

Nesta montagem começamos a perceber o projeto do boneco como ponto de partida, considerando-o uma perspectiva do caminho em potencial a ser trilhado na construção, mas podendo ser alterado de acordo com as necessidades da cena ou da manipulação.

Assim, com a primeira estrutura dos bonecos pronta, iniciamos os ensaios. E, de acordo com nossas propostas de cena, foram realizadas alterações nos mecanismos dos bonecos que não estavam previstas no projeto. Desligamos-nos da obrigação de cumprir o proposto no desenho e libertamos nossa criação aos limites da cena.

Contribuindo a essa pesquisa, tínhamos o problema já citado da falta de orçamento. Como matéria-prima, usamos caixotes de feira, mdf e jornal. Esses materiais sugeriram também algumas modificações no projeto, que com o tempo foram acontecendo de forma natural.

Seguido a esta peça, em 2011 montamos Dum Dum Cererêe - adaptação de uma história folclórica, narra a trajetória da Mariana, menina sapeca, que ao passear em noite de lua cheia, encontrou o Dum Dum Cererê, o bicho papão dos seus pesadelos - com marionetes e boneco habitável. O processo de montagem deste foi próximo ao do espetáculo passado. Pesquisamos outros materiais, o mdf não funcionou, então substituímos nos bonecos do Dum Dum pelo metal encontrado na carcaça do CPU de computador.

Esses bonecos também foram alterados ao decorrer do processo, de uma maneira mais controlada, principalmente devido à técnica de manipulação escolhida. Necessitamos que os bonecos de fio estivessem em uma etapa evoluída do processo de construção para iniciarmos os ensaios.

Os quatro espetáculos relatados acima formaram um grande aprendizado para nós, construtores e manipuladores do Grupo Faz de Conta. E nos possibilitou chegarmos ao nível da pesquisa que propomos na nossa última montagem: Cerrado, entre cascas $e$ raízes.

\footnotetext{
${ }^{5}$ Rafael Mazer é integrante do Grupo Faz de Conta e pertencente à família desde 2009.
} 
Como linguagem cênica, utilizamos para este trabalho uma profícua pesquisa em torno do teatro, música, dança circo, audiovisual e teatro de bonecos gigantes, valorizando e investigando o conceito de artes integradas.

Os bonecos deste espetáculo tinham como proposta serem construídos de materiais descartados e reutilizados e de matéria prima residual do Cerrado. O que ampliava nossa pesquisa quanto ao material.

Para concebê-lo, foi realizada extensa pesquisa de campo que envolveu Unidades de Conservação, Terras Indígenas, Comunidades Quilombolas, instituições e muita gente do campo e das cidades. Daí floresceram histórias, cantigas, rezas, mitologias indígenas, ritmos e informações técnicas.

Em um empenho de criação coletiva, dez artistas em cena e cinco na técnica, plantamos em praça pública um espetáculo multimídia que versa sobre a importância do Cerrado, suas águas, as paisagens, a fauna e flora, a histórica ocupação humana em intimidade com o bioma, a cultura popular, a espiritualidade; e logo o descaso, a ignorância, a degradação, e a urgente necessidade de conservação.

O texto do espetáculo Cerrado, entre cascas e raízes (GRUPO FAZ DE CONTA, 2012) foi construído pelos participantes do grupo em um processo de criação coletiva, aportado pelas pesquisas de campo, assessoria antropológica, pela citação de trechos do livro Caçadas de Vida e Morte ${ }^{6}$ e do conto Pau de Atiradeira ${ }^{7}$.

O espetáculo inicia contando de um Cerrado que está se perdendo, de um povo que está se esquecendo, de um bioma que está sendo devastado. Eu e minha mãe nos encontramos em cena para relembrarmos juntas esse tempo ido. Com minha família reunida e outros companheiros de cena apresentamos brincadeiras folclóricas, cantigas de roda e versinhos improvisados.

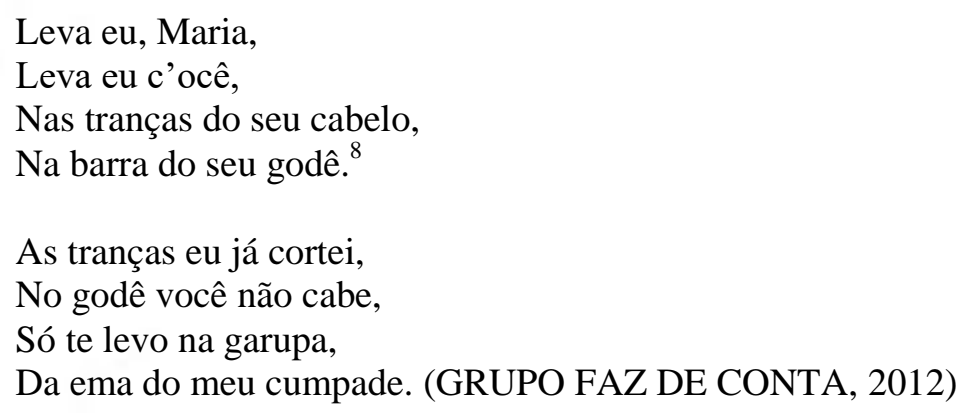

${ }^{6}$ CUNHA, João Gilberto Rodrigues da. Caçadas de vida e de morte. São Paulo: Fundação Peirópolis, 2000.

${ }^{7}$ MENDONÇA, Maria Inês. Pau de Atiradeira. In: LIMA, A. et al. Contos e crônicas. Uberlândia: Sec. Mun. Cultura, 2012

${ }^{8}$ Cantiga das fiandeiras da comunidade de Morada dos Bagres / Vazante- MG, recolhida pelo Grupo Faz de Conta em pesquisa de campo, no ano de 2011. 
Então entrava em cena a Ema, o primeiro boneco do espetáculo. A Ema era um boneco habitável que a atriz Maria Inês comandava de cima de uma perna de pau, que figurava as pernas da Ema. Ela entrava respondendo a um coro que já estava em cena. Este boneco teve uma construção relativamente simples. Apesar de ter sido feito um projeto que apresentava somente algumas instruções gerais para a construção, nós já tínhamos uma idéia clara sobre o que faríamos.

Depois da estrutura feita a atriz/manipuladora em alguns ensaios sugeriu algumas mudanças que foram realizadas facilmente. Este foi um boneco que transitou pouco entre a oficina e a sala de ensaio, pois já sabíamos o que faríamos e sua concepção não é uma idéia inovadora.

A cena da Ema abria para outras cenas que traziam informações sobre a biodiversidade do Cerrado e levantava a questão do fogo, que atualmente representa um grande problema para o bioma.

Fotografia 1: Ema e Palhaço Pequi

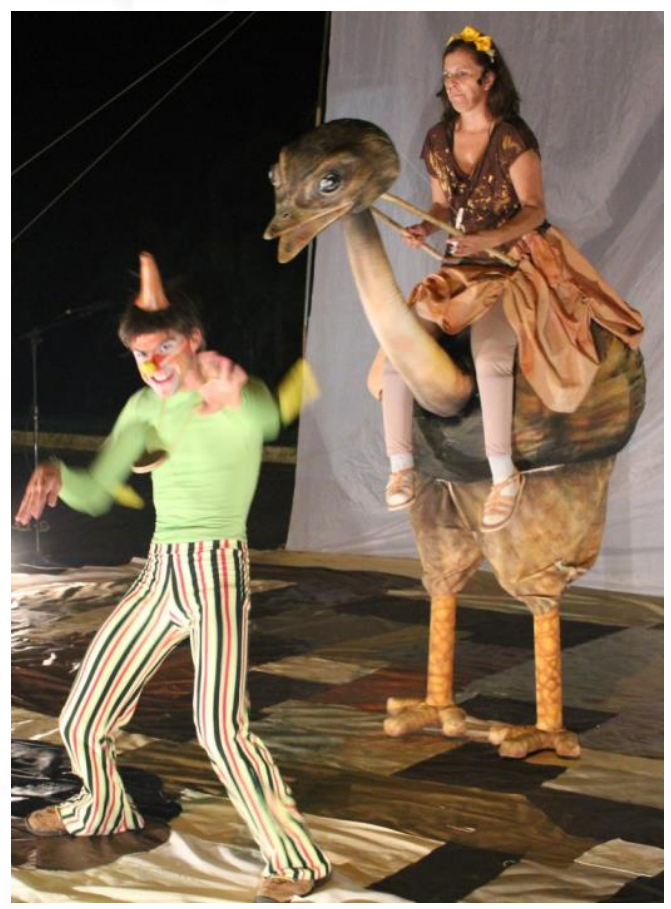

Fonte: Espetáculo Cerrado, entre cascas e raízes. Autor: Bruno Merola 
Após um vídeo que apresentava um panorama do Cerrado pós queimada, de destruição e cinzas, entrava nosso segundo boneco: o Lobo Guará.

Foi com este boneco que o grupo realizou o seu desejo mais almejado: o de fazer um boneco simples. Com certeza esse é o boneco mais simples estruturalmente e mais funcional que o Grupo Faz de Conta construiu em vinte anos.

Não houve projeto. Não houve idas e vindas entre oficina e sala de ensaio.

A concepção estava pronta nas nossas mentes. Pernas-de-pau feitas de andiroba para as patas traseiras; muletas grandes feitas de galhos de ipê para as pernas da frente; um capacete com uma armação de arame revestido por papel de pão formava a cabeça e uma grande manta de retalhos de tecido ganhados de uma loja de estofados dava o acabamento final. Simples assim, esse boneco ganhou um brilho extraordinário em cena.

O Lobo Guará entrava na cena trazendo o mito de origem Maxakalî ${ }^{9}$ sobre a primeira mulher de barro. E então a atriz Camila Merola ${ }^{10}$ dançava o inicio da humanidade.

Fotografia 2: Lobo Guará e a Primeira Mulher

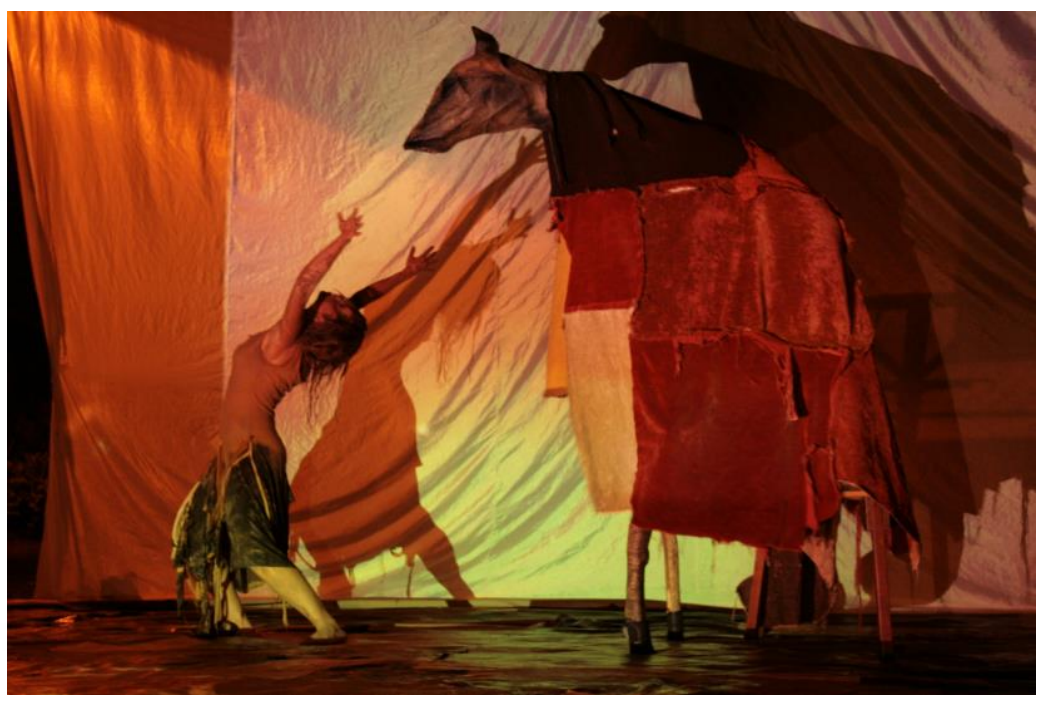

Fonte: Espetáculo Cerrado, entre cascas e raízes. Autora: Tayná Mendonça

Depois desta cena, seguíamos para o momento do espetáculo que nomeei De boi à vaca. Minha primeira partitura, embrião desta parte da peça, foi elaborada a partir de um

\footnotetext{
${ }^{9} \mathrm{O}$ povo Maxakalí vive hoje na Terra Indígena Maxakalí, vale do Mucuri, nordeste de Minas Gerais, território cerradino. Neste mito, os Maxakalís contam que a primeira mulher surgiu do barro e teve por amante o lobo. Da mulher de barro surgiu a humanidade.

${ }^{10}$ Camila Merola é integrante do Grupo Faz de Conta e pertencente à família desde 2010.
} 
exercício cênico proposto pelo diretor do espetáculo, Marcelo Ribas ${ }^{11}$. Nesse, eu tive a intenção de apresentar o instante que o homem selvagem, questionador, era domesticado ou alienado pelos meios de comunicação. Para tanto me amarrei com cordas e entreguei as pontas aos meus colegas de cena.

\section{Eu-Boiadeiro entra em cena.}

Eu-Boiadeiro toca boi-público.

Aôôôôô, boi, sossega!

Eles brigavam com o garrote cara-macau. Tentavam educar o bicho para o carro de bois.

Eu-Boi enfrenta o público.

Pula, dá coice, ameaça chifrada.

Eu-Boiadeiro.

Bicho fortaleza, tinha corpo e promessa para o ofício, de menos a vontade de trabalhar.

Pintado!!! Pintado, esse era o batismo do cara-macau. Pintava mesmo era o sete.

Eu-Boi pinta o sete.

Eu-Boiadeiro.

Pulava cambão, quebrava canzil, fazia de tudo o danado, de menos puxar e trabalhar.

Eu-Preto Velho

Bicho, boi, mula, cavalo, bicho tem mania de gente, mania de pessoa.

Esse aí é mais inteligente que ocêis tudo.

Bota esta lona, de leve, em cima da boca e do nariz do boi. Aí ligeiro, aperta a focinheira com o sedenho, e ferra a mão nas ventas do bicho. Afoga duro e de verdade, é pro bicho ficar agoniado e sem ar, sem fôlego nenhum. Mão de ferro e torniquete. Depois bambeia tudo, deixa o bicho respirar e viver.

Público-boiadeiro sufoca Eu-boi.

Luta.

Cansaço.

Ar.

Estado catatônico.

Eu-vaca.

Público-domador entra com plástico filme e me embala.

Eu-vaca masco.

Eu-domadora.

Agora era vaca, deixara sua condição de boi e se tornara vaca.

Sufocaram seus desejos mais selvagens.

Afogaram seus ímpetos e sua rebeldia.

Emplastificaram, rotularam, carimbaram, aliciaram, trancaram, amordaçaram, proibiram, coibiram, torturaram, trancafiaram, alienaram, massificaram...

Ela seguiria suas companheiras, a tendência e a ordem.

Não perguntaria, não contestaria, cagava e andava,

a vaca já tinha ido para o brejo, afinal o leite já estava derramado.

Senhoras e senhores, respeitável público.

${ }^{11}$ Marcelo Ribas dirigiu três montagens do Grupo Faz de Conta: História Contada, O Casamento da Dona Baratinha e Cerrado, entre cascas e raízes. 
Com vocês, ela a não pensante, a ruminante, a tão fatídica, dona das divinas tetas:

Vaca de Presépio!!! (GRUPO FAZ DE CONTA, 2012)

Esse texto foi repartido entre vários atores, e as ações foram reconfiguradas, permanecendo a troca Eu-Boi/Eu-Boiadeiro e de outros atores entre Boi e Boiadeiro.

O encerramento do texto é feito por um apresentador de circo, que entra trazendo a atmosfera de festa e picadeiro, e entre alguns personagens circenses que ele apresenta; entra o Sistema, nosso terceiro boneco.

O Sistema é formado por uma torre de metalon de 1,60 m. de altura, que faz uma alusão a torres de energia. No topo tem uma base giratória onde estão acopladas quatro torres menores que servem como cangalhas para as vacas: Vaca Polishop (com o apresentador entra a partner que coloca alguns acessórios em mim vendidos pela marca Polishop), Vaca Compras (que empurra um carrinho de supermercado), Vaca Trabalho (traz junto ao corpo muitos cabos, computadores, headfones e outros) e Vaca Lazer (tem uma poltrona amarrada à cintura e um controle remoto na mão). Em cima do Sistema, com chicote na mão, a Vênus Platinada - uma atriz com cabeça de TV - dá palavras de ordem às vacas.

Fotografia 3: O sistema

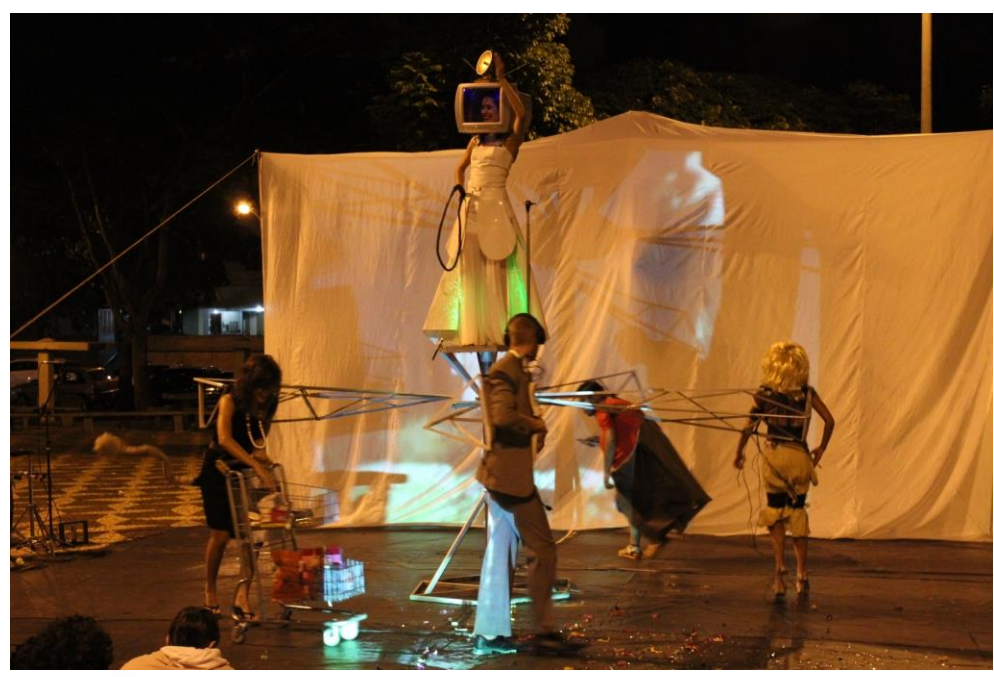

Fonte: Espetáculo Cerrado, entre cascas e raízes. Autora: Anna Bida 
Com essa cena fazemos nossa crítica aos meios de comunicação/alienação e aos sujeitos subordinados a esses. Criticamos o consumismo e a inércia como escolha de vida. Relembramos da responsabilidade individual quanto à degradação do bioma retratado.

Após esse circo de horrores, vamos desmontando toda a cena. As torres/cangalhas são desacopladas do eixo central, os atores se despem, o Sistema é completamente desmembrado e espalhado pelo palco.

No ato final, fazemos uma promessa de fé nas mudanças do homem, no acordar para a possibilidade de uma nova vida, na construção coletiva de uma nova realidade. Estamos seminus em cena, nos revelando intimamente, abertos lançando ao público o desafio de uma nova fase. Um recomeço!

A voz da progenitora de todo o trabalho, da fundadora do grupo, idealizadora deste espetáculo surge como um reconforto, como um grito de levante popular.

Canta a cigarra.

E quanto mais forte canta, mais perto está o giro.

Canta a cigarra para se renovar.

É sua voz que liberta a velha casca, alforria do exoesqueleto.

No auge do grito recupera o silêncio, sua forma primeira de vida.

A cigarra canta chamando a chuva.

Relâmpagos riscam a cena seca. Arde o cerrado em chamas.

O fogo que queima, fascina.

Desperta as sementes adormecidas, o calor esquenta o berço e faz germinar mais vida.

Descem as águas, terra molhada.

O cerrado renasce em brotos.

E, brada, implora, clama aos ofuscados a urgência de mudanças.

Que nossa casa em chamas, em sojas, em pastos aqueça nosso canto.

Que toda a destruição nos desperte o grito.

Planto minhas raízes, sinto meus pés no chão, ouço o som das minhas asas. Semeio liberdade.

Quebro minha armadura, lanço minha casca dura, rompo meu exoesqueleto. (GRUPO FAZ DE CONTA, 2012)

Todos em uma só voz conclamamos: “A cigarra, o cerrado e nós, estamos prontos para um recomeço." (GRUPO FAZ DE CONTA, 2012)

O tecido branco fazendo pano de fundo é puxado e então aparece o nosso último boneco, fruto dessa pesquisa: o Carcará! 
Fotografia 4: Carcará

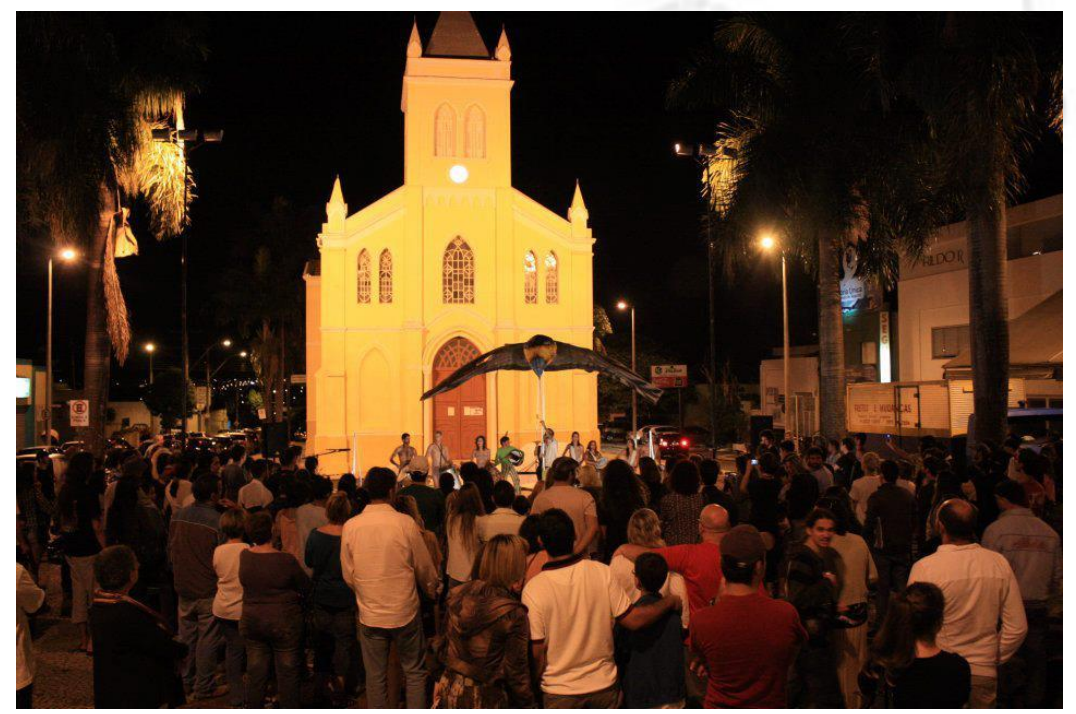

Fonte: Espetáculo Cerrado, entre cascas e raízes. Autora: Pollyana Mendonça

O Carcará é um boneco gigante com quatro metros de altura, seis metros de comprimento e seis metros de largura. Levou dez meses para ser construído. Foram inúmeras idas e vindas entre a oficina e a sala de ensaio. Mesmo aparecendo só ao final do espetáculo e dando um giro breve entre o público.

Esse boneco foi totalmente construído ditado pela montagem da pequena cena que faria e das necessidades da peça. Na concepção era pra ser um boneco menor, bem mais simples até, mas durante o processo do espetáculo, o Carcará foi ganhando dimensão, foi se avolumando, pedindo mais manipuladores, mais mecanismos e articulações.

Ganhou o espaço de ciclorama. Manteve-se calado, quieto, na espreita, como uma verdadeira ave de rapina; recebeu vídeos na sua cobertura, sombras brincaram em seus contornos, fizeram de suas ferragens uma mata. Ele, gigante imponente, esperando seu momento de voar em rasante sobre a platéia que se deslumbrava com o portento.

E nós, construtores e manipuladores, corremos frenéticos durante dez meses, testando materiais, que adquirimos no ferro velho; pesquisando aerodinâmica, eixo gravitacional, distribuição de peso. E, quando acreditávamos que estávamos próximo ao fim, o espetáculo exigia mais. Um boneco maior, talvez, ou quem sabe com mais movimentos. E lá íamos nós para a oficina a nos dedicar ao símbolo do espetáculo. Tantas vezes nos empolgamos com uma grande conquista, tantas vezes nos frustramos com um quebrado na asa, ou entortado na haste de sustentação. 
Iniciamos através deste boneco uma pesquisa sobre a metodologia de construção em diálogo íntimo com a montagem do espetáculo, recebendo interferências, fazendo sugestões, se modificando e modificando o todo, criando possibilidades para o teatro de animação.

E no final, descobrindo o tecido branco, e mirando de frente a reação de surpresa do público. Investimos nosso brado para o Carcará, para o Cerrado e para o Grupo Faz de Conta:

Avôa!

\section{REFERÊNCIAS}

CUNHA, João Gilberto Rodrigues da. Caçadas de vida e de morte. São Paulo: Fundação Peirópolis, 2000.

DIÉGUEZ, Ileana (Comp.). Des/tejiendo escenas. Desmontajes: procesos de investigación y creación. México: UIA-CITRU-INBA-CNA, 2009.

FIANDEIRAS. Cantiga popular. Morada dos Bagres / Vazante- MG. Recolhida pelo Grupo Faz de Conta em pesquisa de campo, no ano de 2011.

GRUPO FAZ DE CONTA. Cerrado, entre cascas e raízes. Uberlândia, 2012.

MENDONÇA, Maria Inês. Pau de Atiradeira. In: LIMA, A. et al. Contos e crônicas. Uberlândia: Sec. Mun. Cultura, 2012. 